\section{Norbert Elias e uma narrativa acerca do envelhecimento e da morte}

\section{Norbert Elias and a narrative about ageing and death}

Alarcon Agra do Ó

Professor da Unidade Acadêmica de História e Geografia / Universidade Federal de Campina Grande Rua Adelino Barbosa de Melo, 150, bl.A, apto.1 58105-678 Campina Grande - PB - Brasil alarconagra@oi.com.br

Recebido para publicação em março de 2007. Aprovado para publicação em julho de 2007.
AGRA DO Ó, Alarcon. Norbert Elias e uma narrativa acerca do envelhecimento e da morte. História, Ciências, SaúdeManguinhos, Rio de Janeiro, v.15, n.2, p.389-400, abr.-jun. 2008.

\section{Resumo}

Este artigo aborda contribuições de Norbert Elias (1897-1990) para a problematização da velhice, mediante a análise do seu texto "Envelhecer e morrer". O sociólogo é aqui tomado como o autor de textos que podem vir a contribuir para a construção de referências que transcendam os limites disciplinares, ou mesmo a polarização entre saberes 'da saúde' e 'do social', e possibilitem atingir um desejado campo de estudos sobre o envelhecimento. Ainda que, em alguns momentos, compactue com idéias próximas à idealização da 'Era de Ouro' précapitalista da velhice, Elias oferece ao leitor pistas instigantes que merecem ser levadas em conta, sobretudo quando relaciona a experiência contemporânea da velhice à invenção da própria modernidade.

Palavras-chave: velhice; morte; sociologia médica; Norbert Elias (18971990).

\section{Abstract}

This article investigates the contribution made by Norbert Elias (1897-1990) to the problematization of old age by analyzing his text "Envelhecer e morrer". Here, the sociologist is seen as an author of texts which can help build up references that span disciplinary boundaries, or even overcome the polarization between 'health-' and 'social-'related knowledge, making it possible to form the desired field of study on ageing. Though Elias sometimes aligns himself with ideas bordering on an idealization of ageing from a pre-capitalist 'Golden Age', he does offer insights which deserve to be taken into consideration, especially when he relates the contemporary experience of ageing to the invention of modernity itself.

Keywords: old age; death; medical sociology; Norbert Elias (1897-1990). 
$\mathrm{O}$ objetivo deste artigo é descrever e analisar as formas pelas quais Norbert Elias produziu, no texto "Envelhecer e morrer", uma imagem singular em relação à experiência da velhice, referindo-se simultaneamente à sua história pessoal e à sua trajetória de cientista social. Interessa chamar a atenção principalmente para as possibilidades, abertas por Elias, de novos diálogos entre os saberes 'da saúde' e as ciências sociais. ${ }^{1}$

Uma das faces da velhice, no presente, consiste em ter-se tornado objeto de atenção de um crescente número de práticas de saber e de poder. Alertados pelas transformações demográficas, que indicam o aumento da população idosa e da expectativa de vida, mas mergulhados num mundo que trama a si próprio com os fios da valorização da juventude, os pesquisadores de diversas áreas têm inserido, cada vez com mais freqüência, questões relacionadas à velhice e ao envelhecimento no mapa de seus interesses de estudo (Debert, 1999; Minois, 1999; Motta, Azevedo, Gomes, 2005; Prado, Sayd, 2006, 2007; Witter, 2006).

É importante observar que tal tendência não tem sido vivida, pelo menos no Brasil, de forma homogênea; há, aqui, espaços mais sensíveis à problematização da velhice, ao lado de alguns silêncios. Assim, é mais comum encontrarmos estudos nas áreas de nutrição, psicologia, saúde pública e coletiva, enfermagem, para não falar nas mais 'óbvias', de geriatria e gerontologia. No âmbito das ciências sociais, há um sensível predomínio de estudos nas áreas de sociologia e de antropologia, em detrimento, no entanto, da história - tão interessada na infância, e tão pouco atenta à historicidade de outros recortes etários. A bibliografia, no final deste artigo, ilustra essa advertência.

Outra dimensão desse cenário, que talvez mereça ser destacada, diz respeito a uma perceptível tendência de alguns estudos a praticar abordagens que se valem do cruzamento de saberes distintos. Quando isto acontece, a velhice é constituída como um objeto múltiplo, cuja problematização é potencializada pela contribuição de tradições de pesquisa e de interpretações a princípio particulares (Debert, 1999; Prado, Sayd, 2006, 2007). Nesse sentido, a velhice aparece tematizada não como um objeto a priori, mas como uma trama complexa, constituída como tal no próprio movimento da investigação. Dessa maneira, cresce a demanda por abordagens que ofereçam alguma segurança epistemológica aos pesquisadores para colocar em debate ferramentas conceituais e metodológicas que possam ser apropriadas e transformadas em condição do pensamento num cenário de tantas experimentações (Groisman, 1999; Prado, 2002).

Em alguns estudos recentes acerca da velhice, o pensamento de Norbert Elias vem sendo acionado - em geral numa aproximação com trabalhos de Philippe Ariès (1981) e de Michel Foucault (1999-2004) - como uma referência importante para a construção de uma narrativa acerca da invenção histórica da velhice ao longo da modernidade (Lopes, 2000). Nesse caso, a obra de Elias é enfocada como responsável por chamar a atenção para os mecanismos de construção simultaneamente social e subjetiva do homem moderno.

A apropriação do pensamento de Elias pelos estudiosos da velhice tem suas razões, e a qualidade intrínseca daquela sociologia é apenas uma das motivações para tanto. É sabido quanto a pesquisa acerca da velhice demanda um maior e mais cuidadoso investimento tanto no que diz respeito aos seus aspectos propriamente ditos empíricos, quanto no que se refere aos seus aspectos conceituais, teóricos e metodológicos. Isso parece ser ainda mais urgente no campo das ciências sociais interessadas em pensar a saúde e, mais especificamente, 
a velhice. ${ }^{2}$ Nesse sentido, a exploração de campos teóricos parece ser um passo importante na consolidação de um esforço de construção, por parte das ciências sociais, de um espaço de legitimidade para os estudos dedicados à velhice (Prado, Sayd, 2007; Giddens, Turner, 1999). No entanto, não será esta a preocupação mais relevante deste artigo, ainda que a posição aqui assumida não seja, em momento algum, discordante da apontada acima.

Muito aquém da exploração de uma espécie de agenda para a pesquisa social relativa à velhice, encontrada em estudos de Norbert Elias, o que se procura realizar aqui é, apenas, uma espécie de exploração das bordas de um pequeno texto. Aliás, pequeno mas dotado de uma particular densidade: trata-se de uma fala de Elias, composta para ser proferida num congresso médico no começo dos anos 1980, quando ele próprio já era, aos olhos de todos, inclusive de si mesmo, um homem idoso (nascera em 1897, e a conferência a que nos referimos data de 1983). Não era apenas o pronunciamento de um cientista social: era um idoso que falava, e a partir de um lugar construído na própria fala como marcado pelos sinais da velhice. Além disso, não se tratava de uma fala para qualquer público: dirigia-se justamente a um conjunto de profissionais que, ao longo da modernidade, vem sendo responsável pela demarcação mais precisa e mais eficiente dos limites e das possibilidades da velhice.

\section{A razão de ser do estudo}

O que justifica uma produção dessa natureza, ainda mais se considerada a urgência, rapidamente mencionada acima, relativa à sofisticação do campo de estudos da velhice? Em linhas gerais, dois argumentos podem ser levados em consideração a favor do que se faz aqui. O primeiro, de ordem mais ética, diz respeito à idéia de que, como lembrou ainda nos anos 1940 o historiador francês Marc Bloch, não há prática de saber que seja, a priori, desprovida de seus encantos, de seus méritos. O segundo argumento está relacionado à consideração de que a análise das práticas pelas quais a velhice (e qualquer outra dimensão da experiência social) é tematizada implica não só a exploração de jogos de palavras, mas também, e muito mais, a problematização, que é política, dos jogos pelos quais o sentido é, socialmente, construído e apropriado (Foucault, 1999-2004).

Com relação ao segundo argumento, cumpre ainda ressaltar que o texto de Elias aqui estudado tem uma relevância não negligenciável. Isto se dá porque ele constitui não apenas uma meditação a mais sobre a velhice, mas também uma intervenção, num debate de crescente visibilidade, de um dos sociólogos mais importantes do século XX.

Como se sabe, apesar de a produção de Elias ter demorado por demasiado a obter reconhecimento acadêmico, depois que ele conseguiu se fazer escutar nunca mais o cenário da teoria social pôde demarcar-se sem a consideração de uma ou outra de suas contribuições, ainda que eventualmente ele venha a ser lido de formas pouco felizes, como alguns autores já apontaram (Brandão, 2003; Garrigoux, Lacroix, 2001; Malerba, 2003). Nesse sentido, seu texto sobre a velhice atrai o interesse não só dos pesquisadores em geral das ciências sociais (afinal, parecia ser a indicação de problemas sociológicos singulares), mas principalmente do conjunto heterogêneo daqueles interessados nas questões etárias e, em especial, no envelhecimento. A forte presença simbólica do texto em questão já o credencia como merecedor de uma atenção especial, e é o que se pretende realizar aqui, nos limites deste estudo. 


\section{"Envelhecer e morrer" - as praias de uma fala}

O texto em análise é composto por oito pequenos blocos. Em cada um deles mencionase uma série de questões, e não raro os enunciados são retomados pouco depois de expressos. $\mathrm{O}$ andamento do texto assim como seu título indicam que ele trata de 'alguns problemas sociológicos' envolvidos nas experiências do envelhecimento e da morte. Portanto, além de apontar aspectos das questões levantadas, existe uma tentativa de construção de protocolos explicativos.

De modo geral, a abordagem de Norbert Elias sinaliza para a necessidade de a sociedade contemporânea tomar distância de suas fantasias e seus tabus, ao se acercar de fenômenos como o envelhecimento e a morte. De acordo com ele, a predominância da crença sobre o conhecimento é responsável não só pelo empobrecimento da vida, mas também pela manutenção de relações sociais assimétricas, uma vez que alguns grupos se mantêm detentores de certa supremacia face à credulidade popular acerca de supostos mistérios do mundo e da vida. Quanto a isso é preciso observar, diz Elias, que o processo de civilização a que a sociedade ocidental se submeteu na modernidade silenciou os aspectos naturais e biológicos da velhice e da morte, cobrindo-as com significados culturais que permitem aos indivíduos a elaboração de fantasias que mais atrapalham que auxiliam na construção de uma vida mais digna (Lucena, 2003).

No caso da velhice e da morte, a sociedade moderna empreendeu, segundo Elias, um movimento de retirá-la do espaço público e dirigi-la à esfera privada e ao mundo dos especialistas. O homem comum cada vez sabe menos de si, e cada vez mais depende de ajuda especializada para viver e para morrer, como se sua autonomia houvesse sido, em nome da civilização, seqüestrada por padrões de racionalidade que são, no fundo, mecanismos de construção ou de manutenção de hierarquias e assimetrias sociais. Essa teria sido a forma pela qual nossa sociedade elaborou a sua relação consigo e com a prática da individualização: os afetos foram controlados, os instintos, subjugados à cultura, a felicidade foi relacionada intimamente à satisfação e ao gozo perene do indivíduo. Aos velhos passou a caber apenas a culpa por sua própria decadência e a alternativa do isolamento, sob os cuidados de instituições e especialistas, que os retiram do convívio social, pacificando a sensibilidade dos mais jovens (Agra, 2006; Haroche, 1998; Porter, 2004).

É fundamental observar que, ao enunciar as suas verdades acerca da velhice e da morte, Elias não abdica do seu lugar de sociólogo, mesmo que, contrariando as regras da impessoalidade científica, não hesite em falar usando a primeira pessoa do singular nomeando-se, com insistência, como um sujeito também descrito pelas palavras da velhice. E justamente é da sua experiência privada que ele retira dois pequenos casos exemplares, a partir dos quais inicia a sua exploração do envelhecimento e da morte. O primeiro caso já se dera há muito tempo, mas ainda estava presente o suficiente em sua memória para impregnar-lhe o pensamento tantos anos depois de ocorrido.

Uma experiência de juventude assumiu certa significação para mim agora que sou mais velho. Assisti a uma conferência de um físico muito conhecido em Cambridge. Ele entrou devagar, arrastando os pés, um homem muito velho. Eu me surpreendi pensando: "Por que ele arrasta os pés assim? Por que não pode caminhar como um ser humano normal?" Na hora, me corrigi: "Não pode evitar, é muito velho." (Elias, 2001, p.79) 
O segundo caso se deu quando Elias já havia envelhecido:

Era professor visitante numa universidade alemã e fui convidado para jantar por um colega que estava no auge de sua vida. Serviu-me um aperitivo antes do jantar e me convidou a sentar numa moderna poltrona de lona, muito baixa. Sua mulher nos chamou para a mesa. Levantei, e ele me lançou um olhar de surpresa, talvez um tanto decepcionado: "Puxa, você está em muito boa forma", disse. "Não faz muito tempo, o velho Plessner jantou conosco. Sentou na poltrona baixa como você, mas não conseguiu se levantar, por mais esforço que fizesse. Você precisava ver. No fim, tivemos que ajudá-lo." E ria que ria: "Hahahaha! Não conseguia levantar!" Meu anfitrião se sacudia de rir. Evidentemente, também nesse caso, a identificação entre os não-velhos e os velhos causava dificuldades. (Elias, 2001, p.81-82)

Ambas as histórias servem-lhe para a exploração de uma distância entre dois grupos, por ele denominados 'não-velhos' e 'velhos'. Sob o olhar de Elias, o primeiro deles não consegue compreender a condição dos outros, e essa incompreensão se dá de uma forma naturalizada. Dá-se, ali, a atribuição de normalidade à vida anterior à velhice e, por conseguinte, afirma-se que o envelhecimento retira do indivíduo algo de sua humanidade.

Os não-velhos, diz Elias (2001, p.79), até sabem que "os velhos, mesmo quando saudáveis, muitas vezes têm dificuldades em mover-se da mesma maneira que pessoas saudáveis de outra faixa etária, exceto as crianças pequenas". No entanto é um saber remoto, desprovido de maior substância, de maior impacto na construção de condutas sociais. As pessoas ditas 'normais' não conseguem "imaginar a situação em que suas próprias pernas e tronco deixam de obedecer à sua vontade, como seria normal" (p.79). Elas vêem que isso ocorre com outras pessoas ao seu redor, mas atribuem o fato a um desvio, a uma variação da experiência que excede os padrões legítimos da existência.

Opera-se aí, fundamentalmente, a incapacidade que têm os 'normais' de ocupar, ao menos por um instante, o lugar dos velhos. Elias imagina que isso seja de algum modo compreensível - pois faltaria aos jovens algo importante para a construção de uma relação de identificação com o seu outro, o sujeito velho. De acordo com ele, é importante considerar que "a maioria das pessoas mais jovens não tem base de experiência própria para imaginar o que ocorre quando o tecido muscular endurece gradualmente, ficando às vezes flácido, quando as juntas enrijecem e a renovação das células se torna mais lenta" (Elias, 2001, p.80). Não importa que a ciência, um conjunto de saberes cada vez mais difundido, sob a forma de informações que a todos chegam em algum grau, explique os mais variados processos biológicos relacionados ao envelhecimento. Na ausência de uma experiência vivida no próprio corpo, os jovens não sabem e não compreendem o que é ser velho (p.80).

Assim, Elias opõe duas dimensões do envelhecimento: a sua concepção pelos saberes biomédicos e a sua experimentação pelos sujeitos no tramar de sua própria vida. E, diz ele, entre essas duas velhices, há mais brechas que laços. O crescimento e a consolidação dos saberes científicos sobre a velhice não têm sido suficientes para a disseminação social de uma "compreensão maior e mais detalhada da experiência do envelhecimento, e também da morte" (Elias, 2001, p.80). Isto só seria factível, é o que crê Elias, se fosse possível a produção de uma empatia entre os velhos (que supostamente sabem o que são) e os jovens (que não conseguem saber nada além do seu próprio ser). Essa empatia é dificultada por 
diversas razões, entre elas a dificuldade, por parte do sujeito jovem, de imaginar que um dia seu corpo poderá ser o palco de alguma degradação:

Não é fácil imaginar que nosso próprio corpo, tão cheio de frescor e muitas vezes de sensações agradáveis, pode ficar vagaroso, cansado e desajeitado. Não podemos imaginá-lo e, no fundo, não o queremos. Dito de outra maneira, a identificação com os velhos e com os moribundos compreensivelmente coloca dificuldades especiais para as pessoas de outras faixas etárias. Consciente ou inconscientemente, elas resistem à idéia de seu próprio envelhecimento e morte tanto quanto possível. (Elias, 2001, p.80)

O próprio Elias, na sua trajetória, teria sido presa dessa resistência, conforme atesta o primeiro exemplo relatado em seu texto. Foi necessário que ele mesmo chegasse à velhice para que lhe fosse possível a compreensão de que as pessoas mais jovens, ou de meia-idade, não entendem "a situação e a experiência dos velhos" (Elias, 2001, p.81). Foi necessário que ele se visse como objeto, com certa insistência, de surpresa dos seus contemporâneos, que se impressionavam com sua saúde, com sua aparência saudável (ter saúde e aparentá-la não são, em Elias, séries absolutamente concordantes), com sua natação. $\mathrm{O}$ olhar desse outro, que um dia já foi também o seu, o aprisionou numa identidade não muito confortável.

Sinto-me um equilibrista, familiarizado com os riscos de seu modo de vida e razoavelmente certo de que alcançará a escada na outra ponta da corda, voltando ao chão tranqüilamente a seu devido tempo. Mas as pessoas que assistem a isso de baixo sabem que ele pode cair a qualquer momento e o contemplam excitadas e um tanto assustadas. (Elias, 2001, p.81)

A partir dessas constatações, Elias constrói uma imagem amarga de sua própria época: o tempo em que ele envelhecia era marcado pela inteira ausência, entre os jovens, da sensação de que um dia a velhice lhes atingiria. Seria o presente uma circunstância em que a maior força viva se dava sob a forma do "gozo espontâneo de nossa própria superioridade, e do poder dos jovens em relação aos velhos" (Elias, 2001, p.82). Por sua vez, esse poder é revelado simplesmente pela "crueldade que se expressa na zombaria dos velhos desvalidos" (p.82), e pela construção de uma imagem de feiúra destinada aos personagens da velhice. Não que isso não tenha uma longa história, ressalva Elias, mas a modernização das relações sociais não conseguiu acabar com a desvalorização absoluta da velhice. Isso não seria possível, diz ele, porque o envelhecimento traz consigo uma dimensão que é recusada pela sociabilidade moderna: quando os sujeitos "envelhecem ficam potencialmente ou realmente menos fortes em relação aos mais jovens" (p.82). Sua dependência se acentua, e isso é algo profundamente desprovido de legitimidade no mundo moderno.

A dificuldade da experiência social e subjetiva moderna em assumir a fragilidade e a dependência é tão intensa, que seus protagonistas, no caso os velhos, são capazes de ações surpreendentes, embora não inteiramente dignas, para preservar algum espaço de autonomia. Elias considera que, em certo grau, essa dificuldade é constitutiva da modernidade. Ao tratar dessa questão, não deixa de destacar que a forma pela qual o sujeito vive sua velhice é, em grande medida, uma decorrência de sua experiência passada, dos modos pelos quais sua personalidade e sua inserção social se desenvolveram ao longo da vida. No entanto insiste na idéia de que, seja como for, há uma grande margem de 
declínio do 'poder' e do status das pessoas "quando elas chegam aos sessenta, aos setenta, oitenta ou noventa anos" (Elias, 2001, p.83).

Na construção de um espaço de resistência, diz Elias, há velhos que não hesitam em procurar nos lugares e nas práticas mais inimagináveis algum repouso para a sua criatividade, para a manipulação dos cuidados consigo.

Uma das formas de adaptação a essa situação é a regressão ao comportamento infantil. Não tentarei decidir se isso é simplesmente um sintoma de degeneração física ou uma fuga inconsciente da crescente fragilidade desses idosos em direção aos padrões de comportamento da primeira infância. De todo modo, também representa uma adaptação a uma situação de dependência total que tem seu sofrimento, mas também tem suas vantagens. Há pessoas em muitos asilos hoje que têm que ser alimentadas, postas no vaso sanitário e limpas como crianças pequenas. Também enfrentam o poder como crianças. Uma enfermeira noturna que os trata um pouco bruscamente pode ser chamada de hora em hora durante a noite inteira. Este é apenas um dos muitos exemplos de como a experiência das pessoas que envelhecem não pode ser entendida a menos que percebamos que o processo de envelhecer produz uma mudança fundamental na posição de uma pessoa na sociedade, e, portanto, em todas as suas relações com os outros. (Elias, 2001, p.82,83; grifos do autor)

Elias atenta, também, para "o aspecto afetivo das relações das pessoas que envelhecem e, especialmente, das que estão prestes a morrer com os outros" (Elias, 2001, p.83). Para tratar desse ponto, procura enfocar "o isolamento dos que envelhecem e dos moribundos, que freqüentemente ocorre em nossa sociedade" (p.83). E, para refletir sobre essa experiência, repete um movimento comum em todo o texto (que demarca o olhar sociológico como uma outra possibilidade, diferente do olhar médico) e diz que se interessa mais pela experiência subjetiva daquela condição do que pelas suas dimensões físicas, a seu ver equivocadamente consideradas objetivas.

O seu ponto de partida é a idéia de que a dificuldade dos não-velhos na compreensão dos velhos - e, sem dúvida, da velhice presente em potencial na sua própria vida - é "provavelmente mais evidente nas sociedades desenvolvidas que nas menos desenvolvidas" (Elias, 2001, p.81).

Nesse momento, Elias retoma a generalização que contrapõe a velhice das sociedades pré-industriais ao que ocorre após a modernização capitalista (cf. Prado, 2002). Antes, o envelhecimento e a morte eram circunstâncias vividas sob a responsabilidade da família, diz Elias, o que, se não implicava necessariamente um maior cuidado para com os velhos, pelo menos não levava a um silenciamento acerca da velhice e da morte ou a ocultá-las. Parece ser importante, para Elias, demarcar que a maior diferença entre a velhice vivida antes do capitalismo e a que se tornou possível após sua instalação está no caráter público daquela experiência. Nas sociedades industrializadas, diz ele, embora exista, por um lado, a responsabilidade do Estado pelo velho ou pelo moribundo, existe também o isolamento dessas pessoas, que são assim relegadas ou à solidão propriamente dita, ou à solidão da vida nas instituições (Elias, 2001, p.84-87).

Idosos colocados em instituições, ressalta Elias, são obrigados a construir novos laços, novas redes, e a estabelecer relações sociais num complexo marcado por uma dificuldade a ele inerente. Numa sociedade que privilegia a individualidade, de súbito os idosos são chamados a reinventar parcerias. Além disso, essas instituições são entrecortadas por um 
isolamento em relação a outros sistemas de identidade social. $\mathrm{O}$ asilado deve não só construir novas relações, mas também esquecer as antigas, na busca de "uma vida comunitária com pessoas com quem o idoso nunca teve relações afetivas" (Elias, 2001, p.85). Portanto ocorre a construção de um espaço de absoluta estranheza, que se traduz em problemas relacionados à vida sexual e emocional dos indivíduos condenados a asilos, que, conforme diz Elias, na maioria das vezes não passam de "desertos de solidão" (p.86).

As pessoas do presente não conseguem, lamenta com insistência Elias, "colocar-se no lugar de outras que viveram em períodos anteriores" (Elias, 2001, p.87), e isso implica uma perda muito maior do que a do desconhecimento de outras experiências sociais. Na verdade, acarreta uma possível incapacidade de entendimento acerca da própria experiência presente, uma vez que, nesse caso, não há referências de alteridade que possibilitem compor a própria experiência subjetiva e social. À consideração de tais questões Elias acrescenta a idéia de que, nos últimos tempos, a sociedade ocidental construiu equipamentos e tecnologias cada vez mais eficientes e sofisticados para a interpretação do mundo - especialmente no que diz respeito aos males do corpo. Cada vez mais os saberes sobre o corpo são marcados por uma crescente influência do olhar científico, e graças a isso a possibilidade de explicações fantasiosas ou metafísicas estaria sendo afastada e deixada em segundo plano. Enfim, parece haver maior controle técnico e científico acerca da velhice e da morte, na sociedade contemporânea, do que havia, por exemplo, há duzentos anos (p.86-96).

No entanto, diz Elias, o aumento do saber e das possibilidades de controle sobre a doença, a velhice e a morte não superou completamente a limitação humana em relação à natureza. Por mais adiada que seja, a morte, por exemplo, ela não foi ainda abolida. Conseqüentemente, para muitos indivíduos, ainda é útil - e, mesmo, necessário - conduzir a própria vida a partir da consideração de que há uma ordem que dá sentido ao mundo, aparentemente confuso e irregular. Elias é profundamente crítico dessas práticas, e chega mesmo a afirmar que a superação das crenças em sentidos além da própria materialidade da vida dos sujeitos sociais é uma questão de "amadurecimento da humanidade" (Elias, 2001, p.92). Para ele, a crença numa divindade, ou na natureza (como princípios ordenadores do real) implica a retirada da responsabilidade dos sujeitos, os quais deveriam, isso sim, assumir os riscos de suas ações tanto quanto os seus benefícios.

Os homens, no entanto, lamenta Elias, ainda estão presos às dificuldades de compreensão do mundo. Ainda acreditam que forças extra-humanas dirigem os processos naturais e sociais; ainda regulam suas ações públicas e privadas baseando-se em sistemas de crenças que se definem como posições distantes do que diria a ciência. E, a partir dessa digressão, ele foca sua atenção nos médicos: seriam eles, em face do papel que representam na sociedade, responsáveis pela problematização do caráter humano das escolhas e ações dos sujeitos sociais. Aos médicos caberia, diz Elias, colocar em questão dogmatismos, naturalismos, inclusive superando a própria tendência da medicina em focar-se prioritariamente nos aspectos biológicos da vida. Talvez haja, no presente, a idéia de que a ciência chega, a cada dia que passa, ao seu limite, além do qual não haveria mais o que fazer. Com a introdução, no pensamento acerca de tais questões, de elementos que complexificam o campo, deve-se pensar exatamente o contrário. Deve-se dar, ao idoso e ao moribundo, o direito de saber que o que ocorre com seu corpo não é apenas um 
desdobramento fisiológico de mutações corporais, mas também a repercussão de questões do campo do simbólico e das relações entre sujeitos sociais concretos.

Em todo o seu texto, Elias deseja acentuar o caráter social do envelhecimento e da morte. É o que persegue em meio a considerações, algumas das quais, hoje, após mais de duas décadas, parecem datadas. Preocupa-se, por exemplo, em lembrar que, no presente, devido ao isolamento das pessoas, as crianças não vêem mais a morte, ou os mortos, como ocorria nas sociedades anteriores à industrialização e à modernidade. Entre nós é impedido às crianças o contato com o envelhecimento, com o sofrimento, com a vida, e isso se dá numa época marcada pelo aumento da expectativa de vida. Há um preço a se pagar por tais deslocamentos: "Tudo isso contribui para empurrar a agonia e a morte mais que nunca para longe do olhar dos vivos e para os bastidores da vida normal nas sociedades mais desenvolvidas. Nunca antes as pessoas morreram tão silenciosa e higienicamente como hoje nessas sociedades, e nunca em condições tão propícias à solidão" (p.97, 98).

Por fim, Elias reúne seus argumentos. De acordo com ele, nunca se soube tanto sobre a vida e a morte como na nossa sociedade. Em contrapartida, nunca uma experiência social foi tão segregadora para os que se encontram em situação de doença, velhice e morte. A técnica ocupou todos os espaços, ela foi 'seqüestrada' pela higiene, pela psicologia, pela busca de uma experimentação cada vez mais controlada, cada vez mais regrada do fim da vida. Aos mortos, que antes podiam ter recebido cuidados mais precários, mas que se despediam do mundo cercados pelos familiares e amigos, cabe agora a brutalidade de um isolamento crescente. Não suportamos a dor, o sofrimento, a morte - e, portanto, não suportamos ver quem enfrenta esses territórios. Somos uma sociedade que se abriu para enunciados de paz e de combate à violência, mas paralelamente desaprendemos a conviver com o fim da vida. Mais que tudo, e Elias não esconde o tom de lamento de sua análise, "falhamos ao enfrentar os problemas dos moribundos" (p.102). Essa seria a área na qual a sociologia médica deveria ocupar espaços, finaliza Elias: pensar sobre a condição subjetiva do doente, sobre o papel nada neutro da hipertrofia da técnica, sobre a associação entre velhice, morte e decadência, sobre a constituição sempre ao mesmo tempo social e individual do sujeito, sobre a importância estratégica - na nossa sociedade mais que em outras - do debate sobre todas estas questões.

\section{Considerações finais}

A obra de Norbert Elias tem sido recebida, no presente, como um instigante conjunto de instrumentos teóricos e metodológicos apropriado para reflexões e investigações acerca dos modos pelos quais os indivíduos modernos constituíram a si mesmos e a sua civilização. Portanto, a leitura de "Envelhecer e morrer" deve ter como horizonte a contribuição desse sociólogo para uma teoria da civilização moderna que leve em conta como são importantes, para ela, certas formas de controle das emoções e os sentidos que os indivíduos aprendem socialmente a atribuir a si próprios.

A consulta à produção em geral de Elias, hoje profusamente editada em português, permitiria ainda ampliar o escopo sinalizado em "Envelhecer e morrer". Especialmente para não se compor uma lista demasiado ampla, dois títulos poderiam ser mencionados, 
que também contribuem para a construção de um olhar eliasiano acerca da experiência da velhice. O primeiro deles, "A condição humana" (Elias, 1991), pensado e difundido por ocasião das comemorações do $40^{\circ}$ aniversário do fim da Segunda Guerra Mundial, levanos a pensar, mais uma vez, acerca dos modos pelos quais as sociedades constroem mecanismos de regulação de sua própria violência, a fim de sobreviverem. O segundo, "Sobre o tempo" (Elias, 1998), consiste numa problematização das formas como o homem pensa em si mesmo em relação à sua temporalidade. A partir de ambos é possível refletir, entre outras coisas, com que violência conformamos, no presente, o tempo da velhice. Entretanto coube aqui apenas uma breve referência ao tema, que merece estudos mais aprofundados.

Cumpre lembrar ainda que, para Elias, a análise social deve chamar a atenção para a integração completa, e complexa, entre os indivíduos e a sociedade - uma vez que, segundo ele, as transformações no indivíduo (psicogênese) são séries entrelaçadas com as transformações sociais (sociogênese) e vice-versa. A análise social deve considerar também, diz Elias, a relação entre a civilização e o controle das emoções: quanto mais disciplinada for a sociedade, no que diz respeito às suas tensões emocionais, mais ela será passível de ser considerada civilizada. Esses controles são internos ao indivíduo, sob a forma de autocontrole, e externos a ele, sob a forma de controles sociais que regulam a vida dos indivíduos de acordo com padrões de conduta e comportamento socialmente estabelecidos como válidos.

Para entender a dinâmica de uma certa sociedade, diz Elias, é fundamental observar como, contextualmente, os interesses sociais e individuais se apresentam e articulam. Além disso, é importante examinar também como as relações sociais se dão em meio a redes de interdependência, pelas quais os mais variados interesses se articulam em prol do cumprimento estratégico de objetivos importantes para a coesão social. A civilização, em Elias, não é definida fora da história, fora das relações sociais: é no jogo dos interesses, no embate de forças, que a face da sociedade (sempre mutável) se condensa, dando-se à vida tanto quanto ao estudo.

Essas indicações oferecem possibilidades para a compreensão dos modos pelos quais Elias, no movimento do seu pensamento, configurou a velhice e a morte no texto aqui estudado. Como diz Ricardo de F. Lucena (2003), naquele estudo Elias acionou elementos importantes de toda a sua sociologia, fornecendo uma espécie de síntese de sua obra ao discutir um tema específico tão denso, tão cercado de mistérios e interditos.

De acordo com Elias, vivemos numa época em que um notável desenvolvimento científico mescla-se a um silenciamento ou a uma espetacularização acerca da morte. Essa é uma forma de lhe recusar densidade, e leva a um avançado isolamento emocional, notado pela prevalência do individualismo. Cada vez mais sabemos sobre o corpo e a velhice e, ao mesmo tempo, isolamos a morte no espaço privado e privatizado do interior das câmaras inacessíveis dos hospitais. Mais que isso: somos cada vez menos capazes de nos sensibilizar frente ao momento em que o corpo dá sinais de que se transforma. O nosso desejo é a permanência, é a vida eterna, é a eterna juventude, a rigidez, a força e a beleza. Os nossos maiores temores são o inesperado e a finitude, e deles nos afastamos com vigor. Em tal contexto o velho passa a ser um sujeito vazio, impossível de ser compreendido, em relação 
ao qual não se tem sequer paciência. O velho é aquele outro em relação ao qual o jovem não consegue construir nenhuma identificação. Conseqüentemente não é possível, sem esforço, a solidariedade (entendida como um jogo entre iguais). O idoso é jogado para as margens da experiência social e cultural, e seu acolhimento dependerá de sua incorporação ao mercado.

Há uma sensível antipatia pelos velhos, descritos indistintamente como moribundos, como amontoados de órgãos e não como pessoas humanas. O idoso é pensado atualmente como alguém marcado pelos signos da incapacidade e da dependência. Isso assusta os jovens porque parece ser o seu futuro, e os afasta porque o cuidado é algo desvalorizado no presente, tempo da velocidade e do individualismo. Aos velhos, na sociabilidade contemporânea, diz Elias, só há o acolhimento da caridade ou da condescendência. A eles é impedida a construção de uma vida dotada de sentido, uma vez que acreditam estar vivos quando, na verdade, estão mortos para os outros que o rodeiam.

Elias denuncia, assim, um processo de desindividualização e isolamento do idoso, processo sobre o qual caberia não apenas pensar como também combater. A velhice, para ele, é uma transformação radical na forma pela qual a pessoa se relaciona consigo e com os outros. Dessa maneira, constitui não só uma fronteira ética e política a ser explorada pelas sociedades, mas também um objeto fascinante para o estudioso das ciências humanas. Isso se dá principalmente porque, de certa forma, as atitudes diante do envelhecimento, diz Norbert Elias, são testemunhas do modo pelo qual a sociedade deseja a si própria, pensa a si própria, faz a si própria.

\section{NOTAS}

${ }^{1}$ Este artigo está ligado à pesquisa O Corpo Discursivo da Velhice, em que investigo formas pelas quais a velhice é problematizada em práticas discursivas diversas. Uma versão inicial dele foi objeto de comunicação no $3^{\circ}$ Congresso Brasileiro de Ciências Sociais e Humanas em Saúde, promovido pela Abrasco em 2005.

${ }^{2}$ Aqui, como em alguns outros momentos deste artigo, faço derivar os estudos sobre a velhice de um campo mais geral, que nomeio, não sem ponderar os riscos, de 'estudos da saúde'. Na verdade, faço alusão ao meu próprio percurso de pesquisador, inicialmente interessado numa história da saúde voltada para a investigação dos limites entre a anormalidade e a normalidade no âmbito de discursos médicos e, a partir daí, dedicado a pensar especificamente sobre os modos pelos quais certas práticas discursivas colonizam e interpretam a velhice. Além disso, repercutem também nesse contexto os modos pelos quais os saberes sobre o envelhecimento têm sido estabelecidos no Brasil, onde, em grande medida, sua conformação ainda se dá em relação às (ou na órbita das) ciências da saúde.

\section{BIBLIOGRAFIA}

AGRA, Giscard Farias.

A urbs doente medicada. A higiene na construção de Campina G(g)rande. 1877-1935. Campina Grande: s.n. 2006.

AGRA DO Ó, Alarcon.

Por uma história (cultural) da velhice. Trabalho apresentado no GT História Cultural do XII Encontro Estadual de História da ANPUH/PB: História e Multidisciplinaridade: Fronteiras e Deslocamentos, 23-28 jul. 2006. Cajazeiras. 2006.
ARIÈS, Philippe.

História social da criança e da família. Rio de Janeiro: LTC. 1981.

BARROS, Myriam Moraes Lins de (Org.). Velhice ou terceira idade?: estudos antropológicos sobre identidade, memória e política. Rio de Janeiro: Ed. FGV. 1998.

BOSI, Ecléa.

Memória e sociedade: lembranças de velhos. São Paulo: Companhia das Letras. 1994. 
BRANDÃO, Carlos da Fonseca.

Norbert Elias: formação, educação e emoções no processo de civilização. Petrópolis: Vozes. 2003.

DEBERT, Guita Grin.

A reinvenção da velhice: socialização e processos de reprivatização do envelhecimento. São Paulo: Editora da Unesp. 1999.

ELIAS, Norbert.

A solidão dos moribundos. Seguido de

"Envelhecer e morrer". Rio de Janeiro: Jorge

Zahar. 2001.

ELIAS, Norbert.

Sobre o tempo. Rio de Janeiro: Jorge Zahar, 1998.

ELIAS, Norbert.

A condição humana. Rio de Janeiro: Bertrand Brasil. 1991.

FOUCAULT, Michel.

Ditos e escritos. 5 v. Rio de Janeiro: Forense Universitária. 1999-2004.

GARRIGOUX, Alain; LACROIX, Bernard (Org.). Norbert Elias: a política e a história. São Paulo: Perspectiva. 2001.

GIDDENS, Anthony; TURNER, Jonathan (Org.). Teoria social hoje. São Paulo: Ed. Unesp. 1999.

GROISMAN, Daniel.

A infância do asilo: a institucionalização da velhice no Rio de Janeiro da virada do século. Dissertação (Mestrado) - Instituto de Medicina Social, Universidade do Estado do Rio de Janeiro, Rio de Janeiro. 1999.

HAROCHE, Claudine.

Da palavra ao gesto. Campinas: Papirus. 1998.

LOPES, Andrea.

Os desafios da gerontologia no Brasil. Campinas: Alínea. 2000.

LOUREIRO, Altair Macedo Lahud.

A velhice, o tempo e a morte. Brasília: Ed. UnB. 2000.

LUCENA, Ricardo de F.

Elias: solidão e morte. Conexões, Campinas, v.1. n.1, p.71-78. 2003.

MALERBA, Jurandir.

Historiografia brasileira: a influência intelectual de Norbert Elias. In: Lopes, Marcos Antonio (Org.). Grandes nomes da história intelectual. São Paulo: Contexto. p.524-533. 2003.
MINAYO, Maria Cecília de Souza; COIMBRA JR., Carlos E.A. (Org.). Antropologia, saúde e envelhecimento. Rio de Janeiro: Ed. Fiocruz. 2002.

MINOIS, Georges.

História da velhice no ocidente. Lisboa: Teorema. 1999.

MOTTA, Alda Britto da; AZEVEDO, Eulália Lima; GOMES, Márcia Queiroz de (Org.). Reparando a falta: dinâmica de gênero em perspectiva geracional. Salvador: Núcleo de Estudos Interdisciplinares sobre a Mulher/UFBA. 2005.

PORTER, Roy.

Das tripas coração: uma breve história da medicina. Rio de Janeiro: Record. 2004.

PRADO, Shirley Donizete.

O curso da vida, o envelhecimento humano e o futuro. Textos Envelhecimento, Rio de Janeiro, v.4, n.8. Disponível em: http://www.unati.uerj. br/tse/scielo.php?script=sci_arttext\&pid=S1517 $59282002000200006 \& \operatorname{lng}=\mathrm{pt} \& \mathrm{nrm}=\mathrm{iso}$. Acesso em: 5 maio 2008. 2002.

PRADO, Shirley Donizete; SAYD, Jane Dutra. O ser que envelhece: técnica, ciência e saber. Ciência \& Saúde Coletiva, Rio de Janeiro, v.12, n.1, p.247-252. Disponível em: http://www. scielosp.orgscielo.php?script=sci_arttext\&pid=S1413$81232007000100028 \& \operatorname{lng}=p t$. Acesso em: 5 maio 2008. 2007.

PRADO, Shirley Donizete; SAYD, Jane Dutra. A gerontologia como campo do conhecimento científico: conceito, interesses e projeto político. Ciência \& Saúde Coletiva, Rio de Janeiro, v.11, n.2, p.491-501. Disponível em: http://www. scielo.br/scielo.php?pid=S1413-8123200 6000200026\&script=sci_arttext. Acesso em: 5 maio 2008. 2006.

SIQUEIRA, Renata Lopes et al. A velhice: algumas considerações teóricas e conceituais. Ciência \& Saúde Coletiva, Rio de Janeiro, v.7, n.4, p.899-906. Disponível em: http://www.scielo.brscielo.php?script=sci_arttext \&pid=S1413-81232002000400021\&lng=pt. Acesso em: 5 maio 2008. 2002.

WITTER, Geraldina Porto (Org.).

Envelhecimento: referenciais teóricos e pesquisas. Campinas: Alínea. 2006.

\section{$\rightarrow \rightarrow \rightarrow<<<$}

